\title{
'I think I know a little bit about that anyway, so it's okay': Museum visitor strategies for disengaging with confronting mental health material
}

\author{
Lachlan Dudley*
}

\begin{abstract}
Visitor engagement at museums is an area that has received significant attention from museum practitioners and academics over the last decade. However, very few studies have sought to understand how and why visitors may actively employ strategies to shut down attempts to elicit deep emotional engagement with museum material and messages. This paper looks at an exhibition in a major museum in Australia that discusses mental health and illness. It discusses the high rates of emotional disengagement that were found amongst 172 visitors who were faced with emotionally confronting material and argues that emotions enabled, as well as hindered, constructive, critical reflection amongst visitors.
\end{abstract}

Key words: Mental-health, Museums, Engagement, Disengagement, Empathy

\section{Introduction}

In 2008 the Melbourne Museum opened a permanent and still running exhibition entitled The Mind: Enter the Labyrinth. This exhibition explores the complex and vast subject of the human mind and it exhibits a diverse range of material. Artefacts include cross-sections of human brains that depict damage from malignant tumours, illusion rooms that employ optical mechanics to trick the human brain into misrepresenting the correct size and shape of objects, and a scientology e-meter used by practitioners of scientology to determine a person's mental state. In addition to these objects, contemporary and historic medical tools and restraining material from psychiatric facilities within Victoria are also displayed. The exhibition seeks to challenge visitors' attitudes to normality, and mental health is discussed within the exhibition as part of the overall exploration of the brain and mind.

To date, few studies have sought to make sense of the ways in which general visitors engage with material related to mental health in a mainstream museological institution. The overwhelming majority of studies aimed at evaluating the impact of such exhibitions have focused on the therapeutic benefits that museum visits may offer for sufferers of mental illnesses and have largely ignored the general visitor as a serious component of study (see, for example, Erica et al. 2012; Binnie 2013; Chatterjee and Noble 2013). This represents a missed opportunity to make sense of how visitors engage with a difficult and complex topic that impacts human beings the world over. Indeed, anyone can suffer from a mental illness; it is a widespread phenomenon that transcends boundaries of age, race, nationality and gender.

This paper discusses results from 90 interviews undertaken at The Mind exhibition with 172 visitors in February 2016. One of the aims of these interviews was to determine the degree to which visitors empathetically engaged with the mental health material displayed in the exhibition and, in doing so, it sought to determine the impact the exhibition was having on public perceptions of the mentally ill. Deep imaginative empathy is argued to be central in facilitating challenges to museum visitors entrance narratives or previously held views on particular social or historical topics (Keightley and Pickering 2012; Smith 2016a). The most striking aspect to arise from the interviews was the degree of emotional disengagement 
exhibited by visitors. A significant portion of visitors (56 per cent) either failed to make, or at least acknowledge, any strong emotional or empathetic connection with the mental health material. These visitors exhibited a tendency to make basic, unelaborated statements and often actively or subconsciously employed platitudes that prevented emotional engagement, shut down empathy, and confined their thinking about issues of mental health to an informationbased context. For instance, a number of visitors noted that they 'already knew' about the difficulties faced by those with mental illnesses and, as a consequence, were exempt from having to reflect about mental health issues. It is those visitors who exhibited low emotional engagement and who employed platitudes and similar strategies of avoidance that this paper focuses on. In doing so, it lends strength to findings in Laurajane Smith's $(2010,2011)$ study of exhibitions regarding slavery in England where platitudes were central to visitors who attempted to disengage when emotionally confronted.

The findings of this study also support arguments that visitors to heritage and museum sites seek out and highly value emotionally reaffirming experiences (Bagnall 2003; Poria et al 2003; Smith 2006, 2011, 2015). It draws heavily on Smith's work at difficult exhibitions in Britain and bolsters her argument that emotions play a central and conscious role in helping visitors to critically reflect on difficult material, while also facilitating visitor efforts to distance themselves from certain emotionally confronting aspects of exhibitions $(2006,2010,2011$, 2016; see also Smith and Campbell 2016). In addition, it builds on the work of scholars, like John Falk (2009), who argue that all museum material hits emotional registers whether it intends to or not. As noted by Falk:

Current neuroscience research has shown that learning cannot be separated in the Cartesian sense between rational thought and emotion... all meaning-making, even of the most logical topic, involves emotion, just as emotions virtually always involve cognition...By virtue of its journey through the limbic system, it seems that every memory comes with an emotional 'stamp' attached to it. (2009: 147).

One of the key arguments of this paper is that emotions work to frame and stage the visitor's experience of heritage in museums and that it is impossible to fully understand why people visit museums and heritage sites, and how they engage with such places, without paying sufficient attention to the emotional dimensions of these visits (Smith 2006, 2011; Gregory and Witcomb 2007; Watson 2013; Smith and Campbell 2016). It is certainly true to say that visitors in this study were most critically and fruitfully engaged in making sense of the difficult components of The Mind exhibition when they employed their intellectual, cognitive judgment (if it can be said that there is such a thing separate from emotional reasoning) to think through the emotions evoked by the difficult exhibition material.

This is not suggesting that all emotional engagement equates to deep and critical insight amongst museum visitors. As the work of Smith and Campbell (2016: 444-446) shows, strong emotional responses to material can lead to shallow critical insight or a complete disengagement from the material all together, just as mild emotional responses can result in progressive and profound insights (Smith and Campbell 2016: 444-446). What it does mean, however, is that there is an ongoing need for sufficient attention to be paid to both the combined cognitive and emotional aspects of museum visiting. By adopting this focus we will be better able to understand the complex ways in which museum visitors' emotional and intellectual faculties interact and the implications this has for how they interpret a range of heritage material. Before moving to discuss the findings from the audience interviews at The Mind exhibition, it is helpful to first understand how issues of mental illness have been represented within this exhibition as well as in other museum contexts.

\section{Mental health within museums}

Museums have demonstrated an increased willingness to address a host of difficult issues over the last two decades and a number of studies have explored visitors' emotional engagement at difficult sites (See Sandell 2007, 2010; Smith 2010; Sather-Wagstaff 2012; Schorch 2015). Despite this, the topic of mental health and illness within museums continues to remain 'largely off-limits, approached tentatively and with caution' (Sandell and Nightingale 2012: 24). 
The immense difficulty of encouraging people to develop empowering or empathetic views towards something that is often seen as emotionally destabilizing is clearly understandable (see Corrigan 2000: 53-54; Corrigan et al. 2003; Overton and Medina 2008; Ahmedani 2011). The work of Museologist Nurin Veis (2011) at exhibitions depicting material related to asylums has shown that the topic of mental health is inherently confronting in nature. She argues that it is a subject that requires visitors to engage in the realm of emotion, to feel compassion and empathy for sufferers and, in doing so, to imagine the often-traumatic historic and contemporary realities associated with the treatment and the lived experiences of those who suffer from various mental health disorders (2011: 48-49). It is a topic that can also stimulate dialogue around other emotionally confronting issues of gender, conceptions of normality and changing views of health, wellbeing, life and death (Veis 2011: 48-49).

The challenge of encouraging museum visitors to engage with emotionally confronting material is further highlighted by Heather Battaly (2011). As noted by Battaly (2011: 285), attempts to disengage from emotionally troubling material frequently occurs in individuals if they fail to maintain a clear separation between their sense of self and of the other when engaging with emotionally strenuous material. This can lead to what is known as an emotional over-arousal and an intense desire to disengage. Exhibitions that attempt to stimulate an emotional response in relation to mental health material are therefore likely to face difficulties in prompting the visitor to think through the emotional realities associated with the ongoing legacies of trauma associated with mental health and mental health care.

This does not mean that visitors are incapable of developing the emotional engagement required to assist in altering their views about mental illnesses. Stephen Hinshaw (2007: 42) argues that stigmatized attitudes towards mental health and illness generated by, amongst other factors, western societal outlooks towards medicine, are not hardwired to such a degree as to make them irreversible. Human beings are capable of investing in the 'cognitive and emotional energy' that is required for a more socially aware, balanced and inclusive way of thinking to be generated and sustained (Hinshaw 2007: 42). While this is difficult to achieve, museums are therefore potentially capable of playing a role in arousing reflective empathetic engagement amongst visitors. It is worth mentioning that several recent studies have found that the willingness of museum visitors to utilize their emotional intelligence - the ability to identify certain emotional states and to critically engage with them- was key to this process of rethinking (Smith 2011, 2016; Byrne 2013; Schorch 2015).

Yet research has shown that many depictions of medical and psychiatric institutions in exhibitions and other forms of media have tended to emphasize certain voyeuristic aspects of the history associated with mental health (Coleborne, 2011, p. 21;Veis, 2011, p. 53). This, feels Bronwyn Labrum (2011, p. 66) has come at the expense of a more objective representation of many mental health facilitates and has led to sensationalist and populist interpretations of insanity and asylums. Labrum (2011: 66) argues that many museums tend to present objects, such as straightjackets, restraining cuffs and 'crude' nineteenth century treatment apparatus to attract visitors by portraying asylums as violent and uncaring storehouses of society's unwanted. While ECT machines and restraint jackets were undoubtedly a reality for many psychiatric patients in psychiatric institutions, objects like crockery, sporting equipment used for communal sports days and formal clothes worn on special outings that were also relevant to many patients lives are not accorded the same attention in many exhibitions (Labrum 2011:65-66). As such, Labrum (2011:65-67) contends that recent exhibitions have allowed 'visitors in the present to forget what more recent scholarship on families and asylums has shown', namely that asylums provided a sense of refuge and emotional comfort for many.

Not all museums depicting material related to mental health have followed a sensationalist route and several exhibitions and museums that have explicitly attempted to challenge popular stereotypes about mental health do currently exist. These museums attempt to promote visitors' to think about how societies define health and illness as part of their overall goal of reducing prejudicial stereotypes about mental illnesses. One of these institutions is the Het Deleehoys Museum (2015) in Haarlem, Holland that operates as the national Dutch museum for psychiatry. It is housed in a former mental health institution and is dedicated to encouraging 'visitors to think about the boundary between crazy and normal and question representations of 'madness'. Previous exhibitions at the Deleehoys Museum have covered topics regarding 
social engineering, issues around body image, as well as 'outsider' artwork and the role it can play in helping people to develop a more holistic sense of health and spirituality. Similarly, the Museum Dr. Guislian in Ghent, Belgium is located on the grounds of the former Guslian Asylum and was established due to a lack of understanding about mental health and psychiatry in the general population. It displays, amongst other things, medical objects and artworks by individuals dealing with various mental illnesses and previous exhibitions have looked at the history of the building and the development of 'outsider artwork' and psychiatric practice throughout Europe. The Museo Della Mente (2015) in Rome is a significantly smaller museum that documents the five hundred year history of the Santa Maria della Pieta hospital complex as a hospital for poor foreigners and as a mental institution for the insane. It focuses on 'the fight against the stigma of mental illness and for the promotion of mental health' and has an archival unit and a Centre for Study and Research.

However, to my knowledge, no scholarly studies have been carried out at any of these sites regarding their impact on audience members' views of mental illness and health. There is no way of knowing if these institutions are successfully managing to generate significant and beneficial changes in visitors attitudes and broadening their understanding and empathy towards mental health, or, conversely, if they are resulting in a voyeuristic, hardening of views about the mentally ill.

\section{The Mind Exhibition}

The Mind exhibition in Melbourne, Victoria offers an interesting space to investigate the impact that these sorts of exhibitions and museums are having on visitors' impressions of mental health. The exhibition deals with a range of subject matter ranging from consciousness, brain functionality, and emotional stimulation and is set within a contemporary scientific, biological museum framework (Fox 2002). As noted on the Museum's webpage, the exhibition asks visitors to:

Explore the workings of the mind by entering a world of emotions, thoughts, memories and dreams. Step into the shoes of those that see the world from different mind perspectives. Discover the ways in which drugs and disorders affect our minds and question your attitudes to normality.

The exhibition is darkly lit throughout to provide the impression of entering the unknown and begins with a light-up wall that depicts the many millions of neurons, synapses and neurological pathways that make up the human brain. The visitor then makes their way to the Human Emotions room were different psychological experiments that were used to stimulate certain emotional expressions are discussed. The work of the famous French Neurologist Duchenne de Boulonge is highlighted and a walk-in film is exhibited that attempts to illicit the emotions of fear, disgust, and anger in the visitor by depicting a number of various scenes. For instance, one scene shows an unkempt man who walks up to the screen and who subsequently vomits liquid from his mouth in an attempt to disgust the viewers. Visitors then move to the Ames Room where an optical illusion room is installed. The room has a glass mirror that visitors on the outside can use to look into the room that tricks the brains of the viewers looking in into expanding and contracting the size and shape of visitors who are inside. Visitors then move to the next section of the exhibition that houses a number of Dream Couches. These couches have a video installed in the ceiling that attempts to recreate a number of common dreams, for example flying, falling, forgetting to do your homework, and standing naked in front of a class.

Mental health is addressed throughout the exhibition as a part of this exploration of the human mind and the exhibition 'points towards the importance of continuing to remove stigma around mental health' as part of its aims (Simpkin 2015). However, it is important to note that, unlike the museums previously mentioned, raising awareness around mental health is not the exhibition's primary goal. Mental health is primarily discussed as a means of explaining how the human brain functions and how it can, under particular circumstances, malfunction or operate in a manner that can cause distress. Results from this study must be taken in light of this fact. Yet the topic of mental health is clearly an interesting and important aspect of the exhibition for many visitors. Mental health was brought up unprompted in 89 per cent of the 
interviews that I undertook and was the most popular response when visitors were asked what they felt was the most interesting or important part of the exhibition ${ }^{1}$.

Significant sections of the exhibition contain confronting psychiatric objects and explicitly discuss mental health in detail. For instance, a straitjacket and a confinement chamber that was used to incarcerate former patients at the Kew Asylum in Victoria are displayed within the Dream Room, (the chamber only had enough room for patients to stand in and scratch marks from fingernails were visible on the inside), and tools used for lobotomies and other instruments for drilling into the brain, as well as drugs used to sedate and medicate patients with mental disorders are shown in various sections of the exhibition. Displayed alongside these more 'stereotypical' objects are a range of artworks and audio-visual materials that provide a sensitive and genuine insight into the lived experiences of individuals dealing with a range of mental health disorders. For instance, walk-in audio booths are installed in the exhibition that display videos of actors reading real testimonies of people living with mental illnesses. These testimonies range from difficult and touching accounts of people dealing with bipolar disorders to schizophrenia and were recorded from individuals who were members of SANE Australia (2017), a large organization located throughout Australia that seeks to provide support to those with mental health issues while also educating the public about mental disorders. These are housed in a enclosed room in the center of the exhibition that is accessed through a single entry and exit door. The exhibit also includes a number of art pieces loaned from the Dax Organisation (2016), an art gallery that seeks to develop more nuanced and empathetic views within the community about mental illness by exhibiting artworks created by people with lived experiences of mental health. One of the pieces exhibited in The Mind exhibition shows the drawings of a sixteen-year-old girl suffering from depression who, shortly after drawing her pictures, committed suicide. Another section of the exhibition placed near the audio-visual testimonial booths demonstrates the centrality of empathy to human survival and contains information about how the inherent human fear of the unknown and of the 'other' can be overcome through the development and practicing of empathetic reasoning.

\section{Audience Interviews}

Ninety interviews were recorded at the Melbourne Museum's The Mind: Enter the Labyrinth exhibition with one hundred and seventy two visitors over a two-week period in February $2016^{2}$. The interview sample was comprised of 62 per cent females and 38 per cent males, 75.9 per cent of the sample was under thirty-five years of age, 73 per cent of the sample visited and took part in the interview in groups, and 86 per cent of visitors identified as being of Anglo-Saxon or of Caucasian descent. Women tended to be slightly more empathetic then men, though there was no significant statistical difference in levels of emotional disengagement in relation to age.

Every third visitor was approached and asked if they would be willing to participate in an interview to ensure as best as possible that the sample reflected the overall demographic of visitors to the exhibition. The rejection rate was approximately (8 per cent) and visitors were able to nominate if they wished to do the interview by themselves or participate together if they were visiting with a partner, friend or family member. The exhibition had a single entry and exit located in the same area and visitors were approached as they left the exhibition. Interviews were conducted on a large couch located in a quieter location about twenty meters from the exhibition that received significantly less footfall. This was done to ensure that visitors were physically comfortable and felt confident that their participation in the interview was being largely unobserved by other visitors and that their responses to questions were not being overheard by passers-by to reduce their worry about other visitors making value judgments. In addition, visitors with young children (under the age of 16) were not asked to participate in the study to ensure that the respondents in my sample were as engaged with the interview process as possible. None of the questions explicitly mentioned mental health to ensure that people were not prompted to talk about mental illness if they did not find it to be a meaningful part of the exhibition. ${ }^{3}$

This study followed a similar approach outlined by Smith $(2006,2010,2015)$ in her studies of visitor responses at a range of difficult exhibitions. Visitors were first asked a number of demographic questions to determine their age, gender, occupation and nationality. Sixteen 
open-ended questions followed, only two of which specifically mentioned mental health and were only asked if the visitor independently mentioned mental health during their interviews (see Item One, questions twenty one and twenty two, in the Appendix). The sixteen questions were designed to identify various terms of engagement with the historical and contemporary narratives displayed in the exhibition. Visitors shared their overall impressions and feelings towards the exhibition and their preferences in regards to objects, themes, texts and displays. All interviews were transcribed and read through to identify themes both in relation to each question and within and between interviews as a whole. Each response to individual questions was coded according to the themes that emerged in the initial read through, and the data was analyzed using both NVivo and SPSS. Entire interviews were also coded using the idea of 'registers of engagement' put forward by Smith (2011; Smith and Campbell 2016) - that is, a measure of the level of visitors' overall emotional engagement in relation to the topic of mental health relative to the sample. In relation to this coding for engagement, visitors typically fit into one of five categories measures relative to the interview population, with five representing deep, empathetic engagement, three representing mild, information based engagement, and one representing an explicit disengagement from the material (refer to appendix for in-depth criteria sheet for category qualification).

\section{Findings}

The majority of visitors to the exhibition brought up the topic of mental health during their interview unprompted (89 per cent). However, a significant percentage of all visitors (56 per cent) did not make, or at least acknowledge, any strong emotional or empathetic connection with the mental health material (i.e. below a level four). These visitors exhibited a tendency to either actively or subconsciously disengage with the confronting aspects surrounding the issue of mental health or made basic, clichéd and unelaborated statements about the exhibitions depiction of mental health. For instance, a small portion ( 2.5 per cent) of these visitors, though acknowledging the mental health aspects of the exhibition as important for educating the public, outright refused to engage with these themes due to their confronting nature. Take, for instance, the following visitor who identified the material as emotionally disturbing and who made explicit efforts to remove herself from the situation:

Are there any aspects of your identity that made your visit to this exhibition particularly meaningful or particularly interesting?

[VST 29] Surprisingly, I struggled to watch the mental illness section because I have struggled with depression. So, I found that really confronting.

\section{Which section in particular?}

[VST 29] Just at the end, the booths (displaying stories of real individuals talking about their experience of dealing with various mood and psychotic disorders).

In terms of the confronting aspects, was that a good thing or a bad thing?

[VST29] I felt it was a bad thing. I couldn't watch, I couldn't get all the way through the testimonials.

\section{Is it appropriate that it's in the exhibition?}

[VST 29] Yeah! I think it's appropriate. It's just a personal thing that I would leave. It's the same as if I found another exhibition confronting and I would just move away.

-(Female, 25-34 years of age) 
A similar example of explicit removal can be seen in the following interview in which both respondents, though acknowledging the interest or importance of the material, identify that they would rather 'move on' to a less emotionally confronting part of the museum:

What part or parts of the exhibition did you enjoy most or find most interesting?

[VST 43] It's actually quite a disturbing section. I mean, I found it quite....disturbing (laughs).

[VST 44] Yeah, I could have missed it all and kept on going if I'd known!

[VST 43] I don't know why, it just doesn't feel comfortable.

In a bad way?

[VST 43] No, no.

[VST 44] In a way you don't want to know.

[VST 43] Yeah, I don't want to know what they used to... you know some of the treatments that people used to...

[VST 44] Yeah.

[VST 43] That kind of stuff you've heard about it, but it's a bit full on.

Were there any parts that you disliked or found uninteresting?

[VST 43] No, it was interesting. It was interesting, but it was just a bit uncomfortable because of the content.

How did the exhibition make you feel as you went through it?

[VST 44] Uncomfortable, (laughs).

Will you take anything away in particular from your visit?

[VST 43] For me, I'll be moving onto other exhibitions. I have no interest, (I want to be) moving on.

[VST 44] Yeah... I think it was interesting.

-(VST 43: Male, 35-44 years of age)-(VST 44: Female, 45, 54 years of age)

Both these sets of visitors had strong emotional reactions to the mental health material within the exhibition and, unlike many other visitors interviewed, were able to explicitly identify the material as confronting. Yet their emotional responses functioned to impede their ability to engage critically with the material. The highly personal nature of the exhibition resulted, for these visitors, in a degree of empathetic over-arousal that forced them to disengage altogether.

Other visitors (20 per cent) who exhibited low emotional engagement did not make explicit attempts to emotionally remove themselves from engaging with the material. However, they made simplistic statements about mental health and employed platitudes to avoid engaging in an emotionally meaningful way. In many respects, these visitors were often less emotionally engaged than those visitors who acknowledged their emotional discomfort and who disengaged entirely. The following excerpt from an interview with two visitors represents a typical example from this category of visitor engagement: 
How did the exhibition make you feel as you went through it?

[VST 148] After the sound thing (referring to an interactive sound game where you attempt to remember different noises) pretty stupid, she was pretty good. I'm still looking for something to better her on.

[VST 149] It was pretty good and it was something refreshing. It was good for the memory in terms of what was going on and refreshing what you know.

[VST 148] Refreshing, yeah.

What meaning or importance does an exhibition like this have for contemporary society's understandings of the human mind?

[VST 148] It's important in every way.

[VST 149] Mmmm.

[VST 148] In every way, everyone should check this stuff out all the time.

Could you elaborate a little on why?

[VST 148] Education, information is power. If you don't know things I guess you don't learn anything...

Is there anything you've seen, heard, read today that has altered your views on certain issues or topics?

[VST 148] Yes, she has better hearing than me [laughs].

[VST 149] They already told you that.

[VST 148] Yeah, thanks babe (laughs).

Do you think that museums are an appropriate place to raise the themes, content and messages that were brought up in this exhibition?

[VST 148] Absolutely! The more the better.

[VST 149] Yep. [VST 148] That's what museums should be about.

Will you take anything away in particular form your visit?

[VST 148] No. Not in general. Like I said, most of the stuff I already knew. I was more interested in the old ways they do things, that was eye opening.

[VST 149] Mmmm.

What about the old stuff was interesting?

[VST 148] It was just shocking to see how the brain has been explored over the decades. So, I guess that's all I could really answer.

-(VST 148: Male, 35-44 years of age)

-(VST 149: Female, 25-34 years of age) 
VST 148 begins this interview by offering a joke when asked how the exhibition made him feel. Psychologists and therapists have long highlighted the use of humour as a coping mechanism and as a strategy for deflection (see Lanci and Spreng 2008: 275). He then offers the answer that the exhibition 'is important in every way' when asked about the potential meaning or importance of the exhibition. Yet when pressed to elaborate upon why it is important he reverts to the use of a platitude, 'education, information is power', a vague response that does little to answer the question in any detail. When next asked if they saw anything that altered their views on certain issues, VST 148 again attempts to avoid any serious contemplation of the question by making a joke about one of the hearing activities. He notes that 'Yes, she has better hearing than me [laughs]'. It is only when asked the question 'Will you take anything away in particular from your visit'?, that the visitor begins to demonstrate any real emotional engagement, with VST 148 noting in relation to the old instruments that 'It was just shocking to see how the brain has been explored over the decades. So, I guess that's all I could really answer'. Though showing some degree of emotional and empathetic stimulation beyond an informational level, VST 148 precedes this statement with a platitude, stating that he wouldn't take anything away from the exhibition as, 'Like I said, most of the stuff I already knew'.

This notion of 'already knowing' the information and therefore not needing to engage on any real level of consequence is explicitly repeated in a number of interviews (28.5 per cent) throughout the emotionally disengaged sample. Interestingly, Smith's (2015) study of over 1,000 visitors to a range of museums in England discussing slavery found that many visitors utilized the same platitude of 'knowing' as a means for justifying the closing down of critical reflection. It is worth mentioning that a number of highly engaged visitors from my sample also noted that they felt they already knew about the material regarding mental health. However, it was the defensive manner in which many less emotionally engaged visitors used this phrase that rendered it as an avoidance strategy. Take, for example, the following three excerpts from three different interviews:

Were there any parts that you disliked or found uninteresting?

[VST 60] Maybe where it shows the different parts of the brain because I've already learnt that in school, so I didn't have to pay attention to it.

-(VST 60: Female, 16-24 years of age)

What part or parts of the exhibition did you enjoy most or find most interesting and why?

[VST 28] ...... The dream sequences were interesting, I glanced through stuff about different treatments of medical illness throughout the ages but, again, I think I know a little bit about that anyway so it's okay.

-(VST 28: Female, 55-64 years of age)

Is there anything you've seen heard or read today that has altered your views on certain issues or topics?

[VST 18] A lot of it was a bunch of stuff that I had read before so... It's quite... for me, its basic psychology.

-(VST 18: Male, 25-34 years of age)

These interviewees indicate that they are fully aware of the issues pertaining to mental health 
and illness. They do not simply know about the topic but, in fact, declare they know enough about it. They dismiss the notion that their views could be altered or that the exhibition has anything to offer them in terms of broadening their experience or knowledge in relation to mental health. Indeed, VST 60 indicates that they are exempt from critical reflection on the issue as a result of their previous studies in the area. Much of the emotional energy and skill of these visitors is obviously spent in maintaining a form of emotional distance from the material and, like those visitors who simply chose to disengage, little emotional room is left for imagining or ruminating on the realities that faced mental health sufferers in the past and which continue to face sufferers of mental health issues in today's societies.

The most common visitor response in the sample consisted of visitors (33.5\%) who identified mental health as an interesting, and often the most important aspect, of the exhibition. These individuals often explicitly acknowledged the difficult and emotionally abrasive nature of the exhibition. However, they remained firmly committed to avoiding any deep emotional connection with the material and employed a number of strategies to ensure they discussed mental health and illness within an information dominated context. These visitors rarely attempted to unpack their simplistic expressions of empathy that typically did not extend past statements of generalized sadness or horror.

The following excerpt from an interview with three visitors was typical of visitors who fit this form of mild, information based engagement:

What part or parts of the exhibition did you enjoy most or find most interesting and why?

[VST 162] I found the stuff about the mental health interesting.

[VST 163] The brain.

[VST 164] The personality type things

[VST 162 and VST 163] Oh yeah!

What about the personality type and the mental health did you find interesting?

[VST 162] I think just how we used to treat it compared to how we do now.

[VST 163] Yeah, that box where they used to store people was interesting.

How did the exhibition make you feel as you went through it?

[VST 163] Intrigued.

[VST 164] A little bit tired, it was really dark.

-(VST 162: Female, 16-24 years of age)

-(VST 163: Female, 16-24 years of age)

-(VST 164: Male, 16-24 years of age)

The interviewees begin by identifying mental health as an interesting part of the exhibition as well as highlighting the confinement box, one of the more confronting mental health displays in the exhibition, as being of interest. Though not necessarily a platitude, VST 162, and VST 163 provide responses that conform to other simplistic, information based explanations for enjoyment offered by a number of other similarly engaged visitors (i.e. it widens your horizons, it's interesting to know about the past, knowledge is power, etc.). 
The interview continues:

Were there any specific parts of the exhibition that prompted you to pause for discussion or to share your thoughts with your friends, family, companion or with museum staff?

[VST 162] What did we talk about?

[VST 163] Yeah we talked about something?

[VST 164V3] Oh, the lobotomy?

[VST 162] Oh, yeah! The lobotomy thing.

[VST 163] Yeah, that.

What about it were you talking about?

[VST 163] Just thought it was interesting that they used to do that, I suppose.

[VST 162] Yeah, that they...I don't really remember.

[VST 163] Yeah we talked about personality testing as well.

[VST 164] Oh yeah, like comparing our different personalities.

To try and dig a little deeper, what about those two things did you think was interesting?

[VST 162] I guess, the personality test we related it back to ourselves.

[VST 164] And (we) also (used the personality test to) contrast it with what we thought each other were (i.e. what personality category), like it's interesting if someone thinks they're an introvert but then you think they're an extrovert, it's interesting.

[VST 163] And the lobotomy thing was probably a little bit morbidly interesting.

The interviewees again highlight the confronting mental health aspects of the exhibition as of interest, but do not demonstrate any connection with the personal or human realities represented by the material. For VST 162, the process involved in a lobotomy was nothing more than being 'morbidly interesting'. Indeed, when asked what they talked about, VST 163 offers the response that she 'just thought it was interesting that they used to do that, I suppose', while VST 162 responds 'Yeah, that they... I don't really remember now'. Not only do they make no attempt to establish an empathetic link, they then move to using vague responses and conclude the interview by relying on a common platitude to avoid thinking more deeply about the emotional aspects of what they are seeing. For instance, when asked how the exhibition made them feel, [VST 163] simply offers a single word, 'intrigued', while [VST 164V3] notes it made her feel a little bit tired, and [VST 162] simply does not answer the question.

The interview concludes:

Do you think that museums are an appropriate place to raise the themes, content and messages that were brought up in this exhibition?

[VST 162] Yeah, I think so, definitely!

[VST 163] Yeah, for sure!

[VST 162] I guess, you come here to learn information and it gives you all different perspectives.

[VST 163] Yeah and I think it's important to talk about mental health and stuff like that. 
Why is it important to talk about mental health within a museum context in particular?

[VST 163] I think a lot of school groups come through here and it's important that they get the message in some form, so why not here?

(VST 162 and VST 164 nod to signify that they agree)

The notion of educating others is another reoccurring platitude ( 23 per cent) that arose in the data set of emotionally disengaged visitors. Although highlighting the educational value of the exhibition for others does not represent an inherent desire to avoid answering the question, many of these educational claims by visitors were combined with the notion that there was little left for them to learn on the topic. Take the following excerpt from an interview:

[VST 25]: I think it's good to educate people. Like, we did a subject and we understand but people just come in and be mindblown about stuff that we learn.

\section{-(VST 25: Female, 16-24 years of age)}

By shifting the emphasis of the exhibition onto others, visitors managed to maintain a degree of emotional separation from the material. It was not they that needed to learn or reflect upon the historic and contemporary issues surrounding mental health. Instead, the exhibition would provide other less educated and more uninformed individuals, particularly children, with the chance to explore this important, but, for themselves, already known topic. This shut down any need for empathy as visitors subconsciously declared that they already knew an arbitrary but acceptable amount about these issues. In this way, the notion that the exhibition was useful in educating people was a rehash of the platitude of already knowing about the hardships that face those who deal with mental health issues.

The degree to which a large percentage of visitors empathetically disengaged with the exhibition material becomes apparent when contrasted with those visitors that were highly engaged (11 per cent). These visitors quickly identified the material as emotionally confronting and actively attempted to work through their emotional responses. They did so through the direct use of empathetic reasoning, that is, they made active attempts to place themselves in the position of mental health sufferers on both an intellectual and emotional level and often related the material of the exhibition to their own lives on a deeply personal level. As opposed to platitudes of disengagement, these visitors exhibited a tendency to reaffirm that learning, particularly about historical and contemporary aspects of mental health issues, was not just for others but also for themselves and noted that they would indeed take something away from the exhibition. Take the following two visitors

What part or parts of the exhibition did you enjoy most or find most interesting and why?

[VST 71] Probably the parts about mental disorders because it was a bit enlightening, there was a lot of information there it's very interesting and the history behind mental disorders and the historical treatment.

[VST 72] Yeah, I would have to say the emotional recognition side of it, so it wasn't just a mental disorders, although how that was constructed was freaking amazing, it was just the emotional recognition, the faces, how it was talking about there are these types of emotions, where they stem from, how they can overlay.

\section{What about that did you think was interesting?}

[VST 72] The fact that it was so well explained, the fact that was, Because this is a topic of interest to me, I kind of (am interested) in what people think so having it so clearly explained and none of it was at all offensive which is really hard to find with mental health exhibitions. It was all really clear and it had written cues as well 
as visual images as well as the verbal things, it was just a really good balance.

[VST 71] [It was] Quite easy to understand as well.

[VST 72] Yeah. Yeah. Really awesome.

-(VST 71: Male, 16-24 years of age)

-(VST 72: Female, 16-24 years of age)

The visitors begin by highlighting that their visit was 'enlightening' in relation to mental disorders. It did not, for instance, simply reaffirm their already formed opinions, understandings and experiences of mental health. In doing so, the visitors placed the emphasis of the visit firmly on themselves and allowed themselves the ability to assess what the visit meant for them. This opening up to the possibility of personal reflection is clearly demonstrated in their response to the next question:

How did the exhibition make you feel as you went through it?

[VST 71] Reflective of my own mental well-being.

[VST 72] Yeah, it was quite nice to see that it was solid information. Maybe if... kind of relieved that this information was out there and easy to access.

That's interesting, why relieved?

[VST 72] Because it's not talked about, Mental health isn't talked about and coming from Perth which is a very small, it's basically a big country town, mental health is one of the huge stigmas especially for people around our age bracket. And it's shitty and depressing to see people not get the treatment, not be aware and to mislabel themselves and misdiagnose themselves for attention and for a lack of understanding of what is actually happening to them and others. So, it's just really cool to see it laid out nicely.

Both visitors are engaged here on more than an information-based level. Both are reflecting emotionally on the importance of the exhibition messages as an individual as well as its importance to them in relation to a broader, societal context. VST 72 is, in fact, relieved that the exhibition has brought mental health to the forefront as she feels it is 'shitty and depressing' to see friends and acquaintances suffering from stigma and misdiagnosis. In this way, the exhibition messages, along with the visitor's ability and willingness to engage in empathetic moments, allowed VST 72 to assess the current state of attitudes towards mental health within her hometown through the lens of her own and her friends' experiences. The personal relevance of the material and the interviewees' willingness to reflect is again reconfirmed in relation to the next question:

Were there any specific parts of the exhibition that prompted you to pause for discussion or to share your thoughts with your friends, family, companion or with museum staff?

[VST 71] We actually didn't talk the entire time we went through it. [laughs].

[VST 72] Yeah, we were just sort of enthralled.

Because you guys are going through the exhibition and not verbally talking, was there any moments that you paused by yourselves to reflect on any interesting issues?

[VST 71] I liked in the video where it was talking about emotions. It talked about a mindfulness meditation exercise and that was just a subtle reminder that was just 
like, 'Hey, going for a walk or taking ten minutes out just as a chill can be really beneficial!' So, I really found those (aspects) kind of a nice reminder and I found it a titbit to take away.

Here, Visitor Two VST 71 again places himself, his feelings and his thoughts in direct relation to the exhibition by reiterating the notion that there are messages and even practical advice that he will take away and potentially put into practice. The interview continues:

Are there any aspects of your identity that made your visit to this exhibition particularly meaningful or particularly interesting?

[VST 71] Yeah, I've had mental health issues myself and l've had a lot of friends and family go through the same thing, so it was kind of like a..., that, I guess, is the relief in being there because I do know people that I'm like, 'Hey, if you're going to see an exhibition maybe check out the mind and do some self-reflection in that one!' But yeah, that's kind of it for me, just knowing it.

Is there anything you've seen/heard/read today that has altered your views on certain issues or topics?

[VST 72] The people discussing the... I think it was the same actress talking each time about mental illnesses? But just having [mental health issues] explained with... in the way in which someone does experience it and the progress they went through from diagnosis and how the treatment system they went through. I thought that was really good to see because it made it easily relatable... it kind of made you point out in yourself and realize and go 'Hey! (mental health) That's a (real) thing, cool, sweet'. (it) Just increased awareness.

Will you take anything away in particular from your visit, or more general interest?

[VST 71] For me, it was reminders and just like a mental note to let people who are coming to Melbourne know about the exhibition and just to say that it's a really cool thing to check out!

It is clear to see from this interview that these visitors did not try to close down personal reflection. In fact, much of their energy was devoted to exploring the meanings raised by the exhibition on a deeply personal level and in attempting to establish empathetic connections both to their own lives and to others' lived experiences of mental illness.

The following excerpt provides another example of the willingness to reflect emotionally that some visitors exhibited when contemplating the exhibition material and messages:

What part or pats of the exhibition did you most enjoy or find most interesting?

[VST 191] I think some of the history going back on some of the things they used to do like the horrible lobotomies and that little room they put people in.

[VST 192] The isolation chamber.

[VST 191] The isolation chamber was just...you can't believe people treated people like that.

[VST 192] Horrible.

[VST 191] So, it was quite good seeing the history of it, I think. 
Is there any content or certain messages that the museum has raised here that you particularly agree or disagree with?

[VST 191] Well, I suppose, that we're making good progress. If you look at the history of electric shock treatment.

[VST 192] Yeah, the advances in treatment.

[VST 191] The advances, I think, makes you think, 'Well, we're on the right track', because we just watched that film about Alan Turing the other week and we were thinking that poor man suffered that electric shock treatment. It's so inhumane and awful. I think it makes you feel a bit grateful.

Will you take anything away in particular from your visit?

[VST 191] Well, yeah we'll probably talk about lots of things when we get back.

[VST 192] Yeah, definitely.

-(VST 191: Female, 45-54 years of age)

-(VST 192: Female, 16-24 years of age)

Like the previous interview participants, these visitors demonstrate a degree of empathy that is simply not present in many of the other interviews in the sample.

\section{Discussion}

Though not the only response to the exhibition, significant portions of visitors were confronted and avoided elaborating on the emotional aspects of the material. Many were actively and subconsciously engaged in exerting their energy to shut down deeper thought. Comparisons can be drawn between Smith's (2010) study of visitors to exhibitions dealing with slavery in England where visitors disengaged when confronted in an active effort to keep their emotionally stable entrance narratives intact. In this study, Smith (2010) found that visitors relied on a number of self-sustaining arguments to distance themselves from feelings of guilt. In order to do this, White British visitors would often highlight that they were not personally responsible for slavery ('We're just working class people aren't we? I don't think we can be held responsible for what happened to them" quoted in Smith 2010: 206), or would chose to focus on the fact that Britain was not the only colonial power involved in the slave trade ("... African slavers were Africans and Arabs so all we did was utilise an existing trade, that's all, so we didn't start it..." quoted in Smith 2010: 206). In addition, many of Smith's (2010) sample indicated that the exhibition had little to offer them in the way or learning as they were already aware of relevant issues pertaining to Britain's involvement in the slave trade. Instead, many of the visitors she interviewed spent much of their energy attempting to utilize the exhibition to reinforce views that they held prior to visiting (Smith 2016: 101-102). Similar findings have been noted by Zahava Doering and Andrew Pekarik (1996: 20), whose research found that, typically, the most satisfying exhibitions for visitors were those that operated to confirm and enrich their previously held beliefs and points of view ${ }^{4}$.

This tendency to disengage and distance ultimately poses serious problems to any exhibition dealing with difficult material if, as scholars like Denis Byrne (2013) contend, empathy plays a central role in conveying challenging messages and meanings. It also demonstrates that museums may not be as capable of altering visitor opinions on certain contentious topics as recent visitor studies have suggested. For instance, Phillip Schorch's (2015) study of a group of high school students at the Immigration Museum in Melbourne contends that the exhibition helped to unsettle students' notions of 'self' and 'other'. In doing so, this encouraged students' to attempt to engage in less stereotyped understanding of difference. Similarly, Richard Sandell's (2007: 105-172) work at the Ann Frank Museum in Amsterdam suggests that museums hold a privileged space in the landscape of contemporary media as trustworthy and truthful sources. 
He contends that museum can and do, in fact, provide visitors with a public forum and the discursive tools that are necessary to rethink prejudiced modes of representation (2007:175).

The high levels of disengagement witnessed in this study does beg the question, if visitors were so emotionally disengaged with the confronting aspects of this exhibition, yet mental health was listed as the most interesting and important aspect of the exhibition, then what were visitors interested in doing at The Mind exhibition- why did they visit? A potential answer to that question lies in the fact that several of the 56 per cent of visitors who exhibited basic or low emotional engagement felt they knew enough about mental health so that they did not need to engage, or that it was others who could learn something from the exhibition. As noted, participants who attempted to disengage in Smith's (2010) study of exhibitions regarding slavery did so because it challenged their identity and understanding of historical events. Visitors, far from looking to expand their views on established narratives, wanted to have their sense of self and their commitment to certain ideas re-affirmed, not challenged or undermined. A similar interest in reaffirming a certain sense of identity and a commitment to certain points of view that were associated with this identity, in this case perceived progressive views on mental health, was observed in a number of participants in this study. When asked if their views had been altered on any topics, the most common answer provided was that the exhibition had, in fact, reaffirmed their previous progressive understandings of the mind and mental health ${ }^{5}$. In essence, a significant portion (43 per cent) of the disengaged visitors appeared to be less interested in establishing deep emotional links with mental health material or in reflecting on the ongoing trauma and difficulties that sufferers of mental health continue to experience. Instead, they were more concerned with reaffirming their identity as individuals who held progressive and liberal views towards mental health.

Another explanation for the high levels of disengagement witnessed in this study may be found in the degree to which the mental health components of challenged visitor assumptions of what a 'normal' museum is, how it should function, and what it should represent. Fiona Cameron $(2006,2007)$, in her study of visitor responses to difficult heritage sites, found that museum audiences place great value in the pedagogic and authoritative nature of museums. Based on her interview data, Cameron $(2006,2007)$ suggests that visitors have instilled museums with the authority to present legitimate and sanctioned interpretations of the past. Accordingly, museums are expected to be safe and official accounts of authorized historical narratives (Smith 2006; Ashton and Hamilton 2010). It is possible that museums that fail to fit this criterion of operation are more likely to upset and disturb. A number of visitors in this study, for instance, specifically highlighted that the mental health components of the exhibition were both unusual to find in a museum and unsettling:

Do you think you will take anything away from the exhibition?

[VST 154] Knowledge! (both laugh). I don't know.

[VST 155] It was different to the other ones though (the other exhibitions in the museum), it was a bit out there!

[VST 154] Yeah!

[VST 155] It's something different, you expect dinosaurs and then..

[VST 154] plastic things, but this was kind of... in your face.

-(VST 154: Female, 16-24 years of age)

-(VST 155: Female, 16-24 years of age)

Do you think you will take anything away from the exhibition?

[VST 003] Overall, (it was) enjoyable.

[VST 004] Yeah. It's not something I would have expected to see (in a museum) but it's very well done. 


\section{Why was it unexpected?}

[VST 004] I don't know. It's sort of more of a medical thing, although I realise there are historical things in there too (in the exhibition). I wouldn't have expected to see something so common place. That's not the right word, but it's very well done. I wouldn't have thought to have seen something like that in a million years!

[VST 003] I can't say that l've ever seen anything like that in a museum anywhere else. Anything like that and it would only be like if you went along to... (pause), in fact, I think there's one at the University here. It's a medical museum. I was quite keen but it might have been overwhelming for one of us! (laughs).

-(VST 003: Female, 55-64 years of age)

-(VST 004: Male, 55-64 years of age)

The implications from this study are that a large number of visitors were unable to adequately think through the confronting realities raised by aspects of the The Mind exhibition. As a result, these visitors deny themselves the chance to engage in empathetic reflection. Thus, while the exhibition is bold in its willingness to tackle a difficult and stigmatized issue within society, the quest of The Mind exhibition to challenge peoples' assumptions about normality and health is partially stifled by an emotional unwillingness to participate on its visitors' behalf. It is possible that exhibitions dealing with difficult topics would benefit from considering how to develop different strategies that enable visitors to engage more constructively with their emotional responses (Bonnell and Roger 2007: 6; Smith 2011).

\section{Conclusion}

A number of academics have stressed the idea that museums should act as places of social action. Karen Charman (2013) and Ann Chinnery (2012: 269), for instance, have argued that museums should embrace the role of social advocate, noting that museums can no longer act as detached educators of the public. Instead, Chinnery argues that museums should be viewed by practitioners less and less as 'temples of the muses' dedicated to reverence and contemplation of art and cultural objects. They must be seen, Chinnery (2012) contends, as spaces in which encounters with dialogue, not objects, dominates in an effort to stimulate debate around contemporary social, moral and political issues (2012; 269-272).

Though sound in theory, visitors to The Mind exhibition show that achieving the levels of emotional engagement that are required to develop genuine empathetic connections and nuanced debate on difficult social issues is a difficult task. More thought is needed to better understand why visitors visit difficult exhibitions and what they do when they visit. As has been demonstrated by Yaniv Poria (2003), Smith $(2006,2011)$ and Elasaid Munro (2013), museums are clearly places where people go not just to learn but also to feel. Similarly, the works of Sheila Watson (2015), and Kate Gregory and Andrea Witcomb (2007) have demonstrated that emotions are central to processes of learning and visitor engagement. Visitors in this study often used highly emotive language when relating material to their life. However, it was when visitors felt confronted that emotion and empathy appeared to be switched off. Empathy can therefore be both a hindrance as well as an essential component in enabling visitors to discuss contentious topics in a more engaged and nuanced manner. The challenge ahead for scholars and museum practitioners alike rests in determining how to facilitate meaningful emotional engagement amongst visitors who visit sites that confront and challenge established historical narratives and senses of self and the other. This will only be possible if museum practitioners actively consider empathy and other emotions as primary aspects of the museum visit and if they are made aware of the significant emotional barriers that face visitors at difficult exhibition sites.

Ongoing research by this author is being undertaken with curators, museum visitors and community stakeholders at a number of different sites displaying mental health material in Australia and in England. It is hoped that this research will provide a better understanding of stakeholder interests while also determining the efficacy of a range of different curatorial strategies that are currently being used to display mental health material. 
Ultimately, it may be, as Laurajane Smith notes, that 'the mediation of difficult heritage and history takes time, both in personal and national contexts' (2010: 209). It is certainly possible that in five years' time an increasing public familiarity with issues of mental health, bolstered by representations in different forms of media and ongoing government campaigns, will provide visitors with the emotional tools required to engage more thoughtfully and empathetically with such an exhibition. It is also possible that visitors will continue to disengage with the unpleasant and confronting realities associated with mental health and illness both within a museum and in other contexts. The need to understand what motivates museum visitors and how they engage is therefore important. By neglecting this area of visitor research, we are failing to develop more relevant, informative and socially useful exhibitions.

\section{Limitations}

It is necessary to highlight a number of important limitations of this research and to outline suggestions for further research to adequately address these issues. The Mind exhibition does not hold the raising of awareness and the combatting of stigma around mental health issues as its main focus. In addition, the cohort in this sample was comprised of 75.9 per cent of visitors who were under the age of thirty-five. The majority of visitors were interviewed in groups (73 per cent), and the exhibition was developed almost a decade ago. It is inevitable that the levels of emotional engagement and disengagement with the topic of mental health witnessed in this study were impacted to a degree by these factors. Further studies should be undertaken in contemporary museums and exhibitions that have a specific focus on the topic of mental illness and that are comprised of different types of diversity in the demographic makeup of visitors (i.e. age, visiting in groups or by themselves) to determine what impact these factors may have on engagement with the topic of mental health. Research by this author is currently being carried out at two museums that look specifically at mental health issues in an attempt to address these issues (i.e. The Bethlem Museum of the Mind in Croydon, UK, and at the Wellcome Trust Collection's 2017 exhibition Bedlam: Enter the Asylum, in London).

This study did not involve subsequent follow-up interviews with visitors. It is, therefore, impossible to know what museum messages and meanings visitors may have taken home and extrapolated on in the weeks and months following their visit. The benefits of follow-up studies is borne out by the work of John Falk (2005) and Joy Sather Wagstaff (2012). They highlight how messages taken away by visitors often change several weeks post-visit as the visitor comes into contact with new ideas and viewpoints that trigger a process of rethinking. The way a visitor makes sense of material and messages at the time of visiting can vary drastically in how they view the same material months later. Future visitor studies could accordingly benefit from implementing follow-up surveys into their methodology.

Received: 6 January 2017

Finally Accepted: 3 July 2017 


\section{Appendix}

Item 1

Overall coding of engagement with mental health content and messages

\begin{tabular}{|c|c|}
\hline $\begin{array}{l}1 \text { Active } \\
\text { disengagement }\end{array}$ & $\begin{array}{l}\text { Interviews in this category involved an overall explicit refusal to } \\
\text { engage with confronting mental health exhibition material. These } \\
\text { were often preceded by an acknowledgement of the overwhelmingly } \\
\text { confronting nature of the material and a clear statement that they } \\
\text { chose to disengage. In this way, visitors in this category often had } \\
\text { some of the strongest emotional responses. Yet, their inability to } \\
\text { maintain a sense of emotional separation prompted them to critically } \\
\text { disengage. }\end{array}$ \\
\hline $\begin{array}{l}2 \text { Passive } \\
\text { disengagement/ } \\
\text { basic } \\
\text { engagement }\end{array}$ & $\begin{array}{l}\text { Visitors would often not acknowledge the confronting nature of } \\
\text { the material. If they did, they would rarely follow up or elaborate } \\
\text { on why this was confronting or make attempts to try and unpack } \\
\text { the emotions or ideas that the exhibition aroused. Very few, if any, } \\
\text { emotional statements were made in relation to mental health (e.g. it } \\
\text { was sad, humbling, confronting, uncomfortable, etc.) and they often } \\
\text { used strategies to avoid discussing the topic. } \\
\text { Other visitors that fit into this category simply didn't mention mental } \\
\text { illness as an interesting or relevant part of the exhibition. }\end{array}$ \\
\hline $\begin{array}{l}3 \text { Information } \\
\text { based } \\
\text { engagement }\end{array}$ & $\begin{array}{l}\text { The visitor could be quite engaged with the topic of mental health } \\
\text { and illness and the difficult nature of the exhibition was sometimes } \\
\text { identified. However, emotional statements made by the visitor } \\
\text { tended to be simplistic in nature (e.g. it was sad, the confinement } \\
\text { box was unpleasant). Visitors also made little effort to elaborate } \\
\text { upon these emotional statements. They indicated that what they } \\
\text { would take away from their visit was of general interest. If they noted } \\
\text { that the visit had a degree of personal relevance, the emotional } \\
\text { components of this relevance were discussed in simplistic terms. } \\
\text { In essence, though some efforts were made to identify the difficult } \\
\text { emotional nature of the material, references to mental health } \\
\text { remained firmly within an information-based context. }\end{array}$ \\
\hline $\begin{array}{l}4 \text { Medium } \\
\text { engagement }\end{array}$ & $\begin{array}{l}\text { Visitors acknowledged the confronting nature of the material and } \\
\text { made some active efforts to unpack their emotional responses to it. } \\
\text { Visitors reflected on the importance or relevance of the exhibition } \\
\text { material in relation to contemporary issues surrounding mental } \\
\text { health and illness by thinking about the historic and contemporary } \\
\text { experiences of those with mental health issues. However, though } \\
\text { reflecting on some of the difficulties associated with mental illnesses, } \\
\text { visitors often failed to place themselves in the shoes of those that } \\
\text { experience mental health issues. Moments of empathetic reflection } \\
\text { were sometimes coupled with elements of disengagement that } \\
\text { manifested in the form of an unwillingness to extrapolate further on } \\
\text { the issues or emotions they identified, or the infrequent use of mild } \\
\text { platitudes to justify not thinking further. }\end{array}$ \\
\hline $\begin{array}{l}5 \text { Deep and } \\
\text { empathetic } \\
\text { engagement }\end{array}$ & $\begin{array}{l}\text { The visitor has almost always identified the material as confronting } \\
\text { and actively worked through engaging with the emotions that this } \\
\text { confronting experience brought up. They often did so by directly } \\
\text { trying to put themselves in the shoes of those who experienced } \\
\text { mental health issues and typically related the exhibition material } \\
\text { to their life on a deeply personal level. As opposed to platitudes } \\
\text { of disengagement, these interviews were often coupled with } \\
\text { statements that reaffirmed that learning is not just for others but also } \\
\text { for themselves. }\end{array}$ \\
\hline
\end{tabular}




\section{Item 2}

List of questions for visitors to The Mind exhibition at the Melbourne Museum

1. What age category do you fit into?

2. Are you from Melbourne, inter-state or overseas?

3. What are your occupations?

4. How would you define your ethnic background or affiliation?

5. Are you visiting the museum by yourself or in a group?

6. Do you visit museums often?

7. When was the last time you visited a museum and which one was it?

8. Domestic or international museum?

9. What motivated you to visit the museum today?

10. What motivated you to visit The Mind exhibition in particular?

11. What part or parts of the exhibition did you enjoy most or find most interesting and why?

12. Were there any parts that you disliked or found uninteresting?

13. Has anything that you think could be relevant been left out of the exhibition?

14. How did the exhibition make you feel as you went through it?

15. Were there any specific parts of the exhibition that prompted you to reflect on any interesting things and, if so, what sort of things were you reflecting on?

16. Are there any aspects of your identity that made your visit to this exhibition particularly meaningful or particularly interesting?

17. Are there any content or certain messages that the museum has raised here that you particularly agree or disagree with?

18. What meaning or importance does an exhibition like this have for contemporary society's understandings of the human mind?

19. Is there anything you've seen, heard, read today that has altered your views on certain issues or topics?

20. Do you think that museums are an appropriate place to raise the themes, content and messages that were brought up in this exhibition?

21. Is the mental health part an appropriate or important part of it?

22. Is there anything you might get from discussing mental health within a museum context that you wouldn't get from discussing it in other contexts?

23. Will you take anything away in particular from your visit?

\section{References}

Adler, A., Thompson, L., Blair, K., Noble, G., Menon, U., Lanceley, A. and Chatterjee, H. (2013) 'Using museum objects to improve wellbeing in mental health service users and neurological rehabilitation clients', British Journal of Occupational Therapy, 72 (5) 208-216. 
Ahmedani, B. (2011) 'Mental health stigma: Society, individuals, and the profession', Journal of social work values and ethics, 8 (2) 1-14.

Ashton, P., and Hamilton, P. (2010) History at the crossroads: Australians and the past, location: Halstead Press.

Bagnall, G. (2003) 'Performance and performativity at heritage sites', Museum and society, 1 (2) 87-103.

Battaly, H. (2011) 'Is empathy a virtue?', in A. Coplan and P. Goldie (eds.) Empathy: philosophical and psychological perspectives, 277-3. Oxford: Oxford University Press

Binnie, J. (2010) 'Does viewing art in the museum reduce anxiety and improve wellbeing?', Museums and Social Issues, 5 (2): 191-201

Bonnell, J. and Simon, R. (2007) 'Difficult exhibitions and intimate encounters', Museums and Society, 5 (2) 65-86.

Byrne, D. (2013) 'Love \& loss in the 1960's', International Journal of Heritage Studies, 19 (6) 596-609.

Cameron, F. (2006) 'Beyond surface representations: museums, edgy topics, civic responsibilities and modes of engagement', Open Museum Journal, 8 (2) 1-34.

Cameron, F. (2007) 'Moral lessons and reforming agendas: history museums, science museums, contentious topics and contemporary societies', in S.J. Knell, S. Macleod and S. Watson (eds.) Museum Revolutions: How Museums Change and Are Changed, 330-342, Oxford: Blackwell.

Chinnery, A. (2012) 'Temple or forum? on new museology and education for social change', Philosophy of Education Archive, 269-276.

Charman, K. (2013) 'Education for a new museology', International Journal of Inclusive Education, 17 (10) 1067-1077.

Coleborne, C. (2011) 'Collecting pyschiatry's past: collectors and their colelctions of psychaitric obejcts in western history', in C. Coleborne and D. Mackinnon (eds.), Exhibiting madness in museums: remembering psychiatry through collections and display, 14-29, New York, Routledge.

Corrigan, P. (2000) 'Mental health stigma as social attribution: Implications for research methods and attitude change', Clinical Psychology: Science and Practice, 7 (1) 4867.

Corrigan, P., Markowitz, F., Watson, A., Rowan, D. and Kubiak, M.A. (2003) 'An Attribution Model of Public Discrimination Towards Persons with Mental IIIness', Journal of Health and Social Behavior, 44 (2) 162-179.

Creek, J. and Lougher, L. (eds.) (2008) Occupational therapy and mental health, $4^{\text {th }}$ ed, Edinburgh: Churchill Livingstone Elsevier.

Dax, C. (2016). The dax centre, melbournce, victorira, museum webpage,

https://www.daxcentre.org/the-dax-centre-about-us/mission/ accessed 26 April 2017.

Doering, Z., and Pekarik, A. (1996) 'Questioning the entrance narrative', The Journal of Museum Education, 21 (3) 20-23. 
Falk, J. (2005) Understnading museum visitors' motivations and learning, online document, United States, http:slks.dkfileadminuser

uploaddokumenterKSinstitutionermuseerIndsatsomraaderBrugerundersoegelseArtiklerJohn Falk Understanding museum visitors motivations and learning.pdf , Accessed 25 August, 2016.

Falk, J. (2009) Identity and the museum visitor experience, Walnut Creek, California: Left Coast Press.

Fernando, S. (2010) Mental health, race, and culture. $3^{\text {rd }}$ ed., New York: Palgrave Macmillan.

Fox, K. (2012) The design brief: setting a project up for success, http://www.mavic.asn.aul assets/Kathy_Fox_MV_Design_Brief_Pres.pdf, accessed 25 August 2016.

Fawcett, B., Weber., Z. and Wilson, S. (2011) International perspectives on mental health: critical issues across the lifespan, New York, United Kingdom: Palgrave Macmillan

Fernando, S. (2010) Mental health, race, and culture. $3^{\text {rd }}$ ed., New York: Palgrave Macmillan.

Gregory, K. and Witcomb, A. (2007) 'Beyond nostalgia: the role of affect in generating historical understanding at heritage sites', in S. Knell, S. Macleod and S. Watson (eds) Museum Revolutions: How Museums Change and Are Changed, 267-275, Oxford: Blackwell.

Het Dolhuys (2015) Dolguys museum van de geest Dolhuys, Haarlem, Holland, museum webpage, http://www.hetdolhuys.nl/english-info, accessed 26 August, 2016.

Hinshaw, S. (2007) The mark of shame, Oxford, New York: Oxford University Press.

Keightley, E., and Pickering, M. (2012) The mnemonic imagination: remembering as creative practice, New York: Palgrave Macmillan

Labrum, B. (2011) 'Always distinguishable from outsiders: materialising cultures of clothing form psychaitric institutions', in C. Coleborne and D. Mackinnon (eds.), Exhibiting madness in museums: remembering psychiatry through collections and display, 6583, New York, Routledge.

Lanci, M. and Sprend, A. (2008) The therapist's starter guide: setting up and building your practice, New Kersey, Canada: John Wiley \& Sons, Inc.

Mente, M.L.D (2015) Museo Laboratorio Della Mente, museum webpage, Rome, Italy, http:www.museodellamente.iten, accessed 25 August, 2016.

Munro, E. (2013) 'Veil and the politics of community exhibiting: some thoughts from Glasgow', Cultural Geographies, 20 (2) 243-248.

Museum, M.P., (2015). 'Psychiatric museum', Middelfart Psychiatric Museum, http:www. visit-middelfart.comln-intfunenpsychiatric-museum, accessed 25 August, 2016.

Overton, S. and Medina, S. (2008) 'The stigma of mental illness', Journal of Counseling \& Development', 86 (2) 143-151.

Pekarik, J., and Schreiber, J. (2012) 'The power of expectation', Curator: The Museum Journal, 55 (4) 487-496. 
Poria, Y., Butler, R. and Airey, D (2003) 'The core of heritage tourism', Annals of Tourism Research, 30 (1) 238-254.

Sandell, R. (2007) Museums, prejudice, and the reframing of difference, New York: Routledge.

Sandell, R., Dodd, J. and Garland-Thomson, R. (eds) (2010) Re-presenting disability: activism and agency in the museum, New York, London: Routledge.

Sandell, R., and Nightingale, E. (2012) Museums, equality and social justice, Routledge: London and New York.

Sane (2017), 'Mental health and illness', Sane Australia, https://www.sane.org/mentalhealth-and-illness, accesed 20 February, 2017.

Sather-Wagstaff, J. and Sobel, R. (2012) 'From memory to action: multisited visitor action at the united states holocaust memorial museum', Museums \& Social Issues, 7 (2) 179-191.

Schorch, P., Walton, J., Priest, N. and Paradies, Y. (2015) 'Encountering the other: interpreting student experiences of a multi-sensory museum exhibition', Journal of Intercultural Studies, 36 (2) 221-240.

Simpkin, J., 2015, Museum of the Mind email correspondence, 14 March 2015

Smith, L. (2006) The uses of heritage. London: Routledge.

Smith, L. (2010) 'Man's inhumanity to man'and other platitudes of avoidance and misrecognition: an analysis of visitor responses to exhibitions marking the 1807 bicentenary', Museum and Society, 8 (3) 193-214.

Smith, L. (2011) 'Affect and registers of engagement: navigating emotional responses to dissonant heritage', in L. Smith, G. Cubitt, K. Fouseki and R. Wilson (eds) Representing enslavement and abolition in museums: ambiguous engagements, 260-303, New York: Routledge.

Smith, L. (2015) 'Theorising museum and heritage visiting' in A. Witcomb and K. Message (eds) The International Handbooks of Museum Studies: Museum Theory, 459-484, Chichester: Wiley-Blackwell.

Smith, L. (2016) 'Changing views? emotional intelligence, registers of enagement and the museum visit' in V. Gosselin, and P. Livingstone (eds) Museums and the PastConstructing Historical Concioussness, 101-121, UBC Press, Toronto Vancouver.

Smith, L. \& Campbell, G. (2016) 'The elephant in the room: heritage, affect and emotion', in W. Logan, N Craith \& U Kockel (eds) Companion to Heritage Studies, 443-460, Chichester, West Sussex, UK, Wiley Blackwell.

Watson, S. (2015) 'Emotions in the history museum', in A. Witcomb and K. Message (eds) The International Handbooks of Museum Studies: Museum Theory, [page numbers] Chichester: Wiley-Blackwell.

Veis, N. (2011) 'The ethics of exhibiting psychiatric materials', in C. Coleborne and D. Mackinnon (eds.) Exhibiting madness in museums: remembering psychiatry through collections and display, 48-61 New York: Routledge. 


\section{Notes}

$144.9 \%$ percent of participants noted that mental health was the most important or interesting part of the exhibition when asked the question "What part or parts of the exhibition did you enjoy most or find most interesting and why?". This was followed by $43.5 \%$ who nominated non-mental health components as the most interesting facet of the exhibition.

2 ANU ethics clearance was obtained three months prior to undertaking interviews. All interviews were anonymous and all participants were made aware of the data collection, storage and usage procedures used in this study prior to undertaking interviews.

3 The only exception to this is question twenty-one. However, this question was only asked if the participant brought up mental health unprompted in prior questions.

4 Similar findings were outlined in a subsequent 2012 study by Pekarisk and Schreiber (2012: 487 ) that found visitors 'came in knowing what experiences they expected, and they left having found them, regardless of what museum personnel presented to them inside'.

$548.2 \%$ of the sample noted that the exhibition had reaffirmed previous understandings or lent strength to their views, followed by $35.8 \%$ who noted that the exhibition either had not altered their views or that they were unsure if it had.

*Lachlan Dudley is a third-year, PhD student at the Australian National University in Canberra under the supervision of Dr. Laurajane Smith. His PhD is interested in making sense of the varied ways that museum visitors make sense of difficult material and messages at exhibitions that focus on mental health and illness. It has a particular interest in looking at the different strategies that visitors use to engage, as well as disengage, with mental health material.

Australian National University

Email: Lachlanjtdudley@gmail.com

Mobile: 0415669676 (Australia) 